\title{
ESSENTIAL THROMBOCYTOSIS: A CASE REPORT
}

\author{
UDDIN MK ${ }^{1}$, MH SARDAR ${ }^{2}$, HOSSAIN MZ², UDDIN MM ${ }^{3}$, ISLAM MS ${ }^{4}$, \\ BHUYA MK ${ }^{5}$, KOBIR MA ${ }^{6}$, RAHMAN MJ ${ }^{7}$

\begin{abstract}
:
A 50 year old female presented with, tightness of chest and restlessness. Sometimes difficulties in breathing, headache, insomnia and burning sensation felt in the hands and feet. Initially it appears to be a case of ischaemic heart diseases but finally haematological profile reveals it as 'Essential Thrombocytosis' - a rare disease.
\end{abstract}

Key words: Essential thrombocytosis, clonal disorder, mutation.

J Dhaka Med Coll. 2009; 18(2) : 183-184

\section{Introduction:}

Essential thrombocytosis (primany thrombocythaemia) is a clonal disorder. Primary Thrombocytosis involves a multipotent stem cell, as in the other chronic myeloproliferative disorders. It is characterized by megakaryocytic proliferation in the bone marrow and raised circulating platelet number. There are a very small number of reports where more than one family member is affected. Some of these familial cases are due to mutation in the thrombopoeitin gene leading to excess thrombopoeitin production with a resultant thrombocytosis. ${ }^{1,2}$ As with polycythaemia rubra vera, the recent finding of a high frequency of mutation of $\mathrm{Jak}^{2}$ to these patients promises to advance in the understanding of this disorder. ${ }^{3}$

\section{Case report:}

A 50 year old women Presented with shortness of breath, tightness of the chest, restlessness, insomnia and painful burning of the hands and feet accompanied with erythema. Initially it appears to be a case of ischaemic heart disease. The patient is admitted in Female Medicine Unit (FMU), 200 bedded Hospital, Narayanganj on 03-07-2009 for proper management and treatment. On Examination, she was anxious, there was no anaemia, jaundice, cyanosis and organomegaly. Cardiovascacular, respiratory and nervous system reveals normal. X-ray of chest, ECG, Echocardiography and cardiac enzymes were also normal. Haematological investigation shows that $\mathrm{Hb}$ conc. $12.5 \mathrm{gm} / \mathrm{dl}$, Normal PCV, ESR $5 \mathrm{~mm}$ in $1^{\text {st }}$ hour, TC of WBC $10500 / \mathrm{mm}^{3}$, DC of WBC: Neutrophil $60 \%$, Lymphocytes 28\%, Eosinophil 09\% Monocyte 02\%, Basophil-01\%. Platelet count was $22,00,000 / \mathrm{mm}^{3}$. Comments on peripheral blood film (PBF): RBC shows anisochromia with anisocytosis, and platelets are grossly increased in distribution with hyper aggregation and massive thrombocytosis. Bone marrow study reveals-moderately hyper cellular marrow with normal M-E ratio. Erythropoeisis was active and normoblastic. Granulopoeisis was also active and maturing into segmented form. Masses of aggregated platelet with marked increase in megakaryocytes, which are typically larger and have greater segmentation. All other investigations including liver function test, urea, creatinine and lipid profile revel normal. Special investigation e.g. Philadelphia chromosome also reveals negative.

Considering the history, clinical findings and investigations, the patient was diagnosed as a case of essential thrombocytosis (ET).

1. Consultant, 200 beded Hospital, Narayanganj.

2. Assistant Professor of Medicine, Dhaka Medical Collage, Dhaka.

3. Professor, Northen International Medical Collage, Dhaka.

4. Registrar (Medicine), 200 beded Hospital, Narayanganj.

5. Associate Professor of Haematology, Sir Salimullah Medical College, Dhaka.

6. Professor of Haematology, Sir Salimullah Medical College, Dhaka.

7. Professor and Chairman, Department of Haematology, BSMMU, Dhaka.

Correspondence: Dr. Md. Kazim Uddin. 


\section{Discussion:}

Essential thrombocytosis is an uncommon myeloprolipherative disorder of unknown cause in which marked proliferation of the megakaryocytes in the bone marrow leads to elevation of platelet count. ${ }^{3}$ Median age is 5060 years and there is a slight increase in women, the disorder is suspected when elevated platelet count is found, less frequently the first sign is thrombosis, which is the most common clinical problem. The risk of thrombosis rises with age. Patient is expected to have erythromyalgia, painful burning of the hands and feet, but mucosal bleeding occurs occasionally. In this presentation, laboratory finding are that of very high Platelet count $(>22,00,000 / \mathrm{cmm}), \mathrm{Hb}$ level, ESR, PCV are normal and Philadelphia chromosome is negative. Bone marrow examination reveals marked increased in megakaryocytes which is typically large \& with hyper segmentation but in reactive thrombocytosis they are often in cluster. Polycythemia rubra vera could be excluded, if PCV above the normal and Philadelphia chromosome is positive.

\section{Management:}

Principle of treatment is to control the platelet count so as to reduce the risk of thrombosis which is the major clinical problem. Patient may be placed in risk groups according to age, size of platelet count and previous episodes of thrombosis or haemorrhage. In those with high risk, the aim to keep the platelet count below $<6,00,000 / \mathrm{mm}^{3}$, plateletphoresis is very helpful in short term management, low dose Aspirin $(80 \mathrm{mg} /$ day) is commonly used to reduce the thrombotic risk, Hydroxyurea ( 0.5 to $2 \mathrm{~g} / \mathrm{dl}$ ) has been shown more effective agent to reduce the platelet count rapidly.

\section{Conclusion:}

Essential thrombocytosis is an indolent disorder and allows to long-term survival. Average survival is longer than 15 years. ${ }^{3}$ The major source of immobility thrombosis can be reduced by appropriate platelet control. Late in the course of the disease, the bone marrow may be fibrotic and massive splenomegaly may occur. Sometimes with splenic infarction, there is a $10-15 \%$ risk of progression to myelofibrosis after 15 years and a $1-5 \%$ risk of transformation to acute leukaemia over 20 years. ${ }^{3}$

\section{Reference:}

1. Turhan AG, Cashman. JD, Eaves CJ, Humphries RK, Eaves AC. Variable of feature of normal and neoplastic stem cells in patient with thrombocytosis. Br J Haematol. 1992; 82(1): 50-7.

2. Harrison CN, Gale RE, Machine SJ, Linch DC. A large proportion of patients with a diagnosis of essential thrombocythaemia do not have a clonal disorder and may be at lower risk of thrombotic complications. Blood. 1999; 93: 417-24.

3. Alvarez-Larrán A, Cervantes F, Bellosillo B, Giralt M, Juliá A, Hernández-Boluda JC, et al. Essential thrombocythemia in young individuals: frequency and risk factors for vascular events and evolution to myelofibrosis in 126 patients. Leukemia. 2007; 21(6): 1218-23. 